\title{
ALGORITHM TO AUTOMATICALLY DETERMINE THE LENGTH OF A BIVALENT SYSTEM
}

\author{
Paul VASILIU \\ “Mircea cel Bătrân”Naval Academy, Constanța, Romania \\ p_vasiliu@yahoo.com
}

\begin{abstract}
From the point of view of reliability theory, a system can have two stable states: functioning and defect (bivalent system). Any system is a set of elements. Each element in this set can be found in one of the following states: operating state and fault condition. A subset of elements in the running state is called a system link if they only ensure the system works. The length of a bivalent system is equal to the minimum number of elements that the system holds. In this paper we present an algorithm for the automatic determination of the length of a bivalent system, a Matlab script, a case study and subsequent development directions.
\end{abstract}

Keywords: algorithm, link, length, reliability

\section{Introduction}

The plurality of all elements of the assembly of elements that reflect how the state of an S system depends on the states of its components is called a structure.

In the reliability analysis, structures play an important role. In a first step, the structure of the equipment is analyzed, followed by establishing the algebraic expression of the structure function and then constructing a reliability network associated with that equipment.

Considerations regarding complex systems or equipment are based on the following assumptions:

The equipment considered can only be in one of the following states: operating state or fault condition (bivalent system). The considered equipment can be decomposed into $n$ components (elements) $e_{i}$, $i=1,2, \cdots, n$. The set of all these elements is: $E=\left\{e_{1}, e_{2}, \cdots, e_{n}\right\}$.
Each component $e_{i}, \quad i=1,2, \cdots, n$, is associated with a state variable $\mathrm{x}_{\mathrm{i}}$ defined by: $x_{i}=\left\{\begin{array}{lll}1 & \text { if } & e_{i} \text { is in operation } \\ 0 & \text { if } & e_{i} \text { does not work }\end{array}\right.$.

The set of states $X=\left\{x_{1}, x_{2}, \cdots, x_{n}\right\}$ characterizes the set of possible states of the assembly of elements. Obvious, $\operatorname{card}(X)=2^{n}$.

The system $S$ is associated with a state variable $y$ defined as follows:

$y=\left\{\begin{array}{ll}1 & \text { if } S \text { is in operation } \\ 0 & \text { if } S \text { does notwork }\end{array}\right.$.

Let $Y=\{y\}=\{0,1\}$. The $y$ state variable depends on the set of $X$ states.

We can define a function $\varphi: X \rightarrow Y$, defined by: $y=\varphi\left(x_{1}, x_{2}, \cdots, x_{n}\right)$. The function $\varphi$ is called the function of the structure. Since the function $\varphi$ depends on $\mathrm{n}$ independent variables, it is called function of the $n$ order structure. The $S$ system can be identified with the pair $(E, \varphi): S=(E, \varphi)$.

Let the system $S=(E, \varphi)$. The subassembly 
$L=\left\{e_{\tilde{i}} \mid i \in I \subset\{1,2, \cdots, n\}\right\} \subset E$ is called a link if for any $x_{i}=1, i \in I$ and for any $x_{i}=0, \quad i \notin I$ follows: $y=\varphi\left(x_{1}, x_{2}, \cdots, x_{n}\right)=1$.

In other words, a connection of an operating system ( $y=1$ ) is a subset (subassembly) of elements in which all elements are in the running state, the rest of the elements being defective.

By reformulating, a link is a subset of elements that are in a state of operation and which ensure the system's operation if the other elements are defective.

Any system has at least one link.

To determine all system links, calculate the values of the structure function at all points $\left(x_{1}, x_{2}, \cdots, x_{n}\right)$. If $f\left(x_{1}, x_{2}, \cdots, x_{n}\right)=1$ for $x_{i_{1}}=x_{i_{2}}=\cdots=x_{i_{p}}=1$ and $x_{i}=0$ for any $i \in\{1,2, \cdots, n\} \backslash\left\{i_{1}, i_{2}, \cdots, i_{p}\right\}$ then the

$\begin{array}{ll}\text { subset of elements } & \text { of } \\ \text { subassembly of elements) }\left\{e_{i_{1}}, e_{i_{2}}, \cdots, e_{i_{p}}\right\}\end{array}$ is a link.

Let $l_{k}>0$ the number of links with $k$ elements, $k \in N^{*}$.

It is called the length of the system $S$ number $\lambda(S)=\min \left\{k \mid l_{k}>0\right\}$.

The study of the links and length of a system brings important information about the operation of the system under the condition that some of the component elements are defective.

The difficulty of manually determining links and the length of a system increases as the number of elements in the system increases. There is a need to simplify and automate the determination of system links and system length. For this reason, the authors wrote the Matlab functions presented in Section 2.

\section{Matlab implementation}

The Matlab main function with the signature function links(n) receives the $n$ value of the input. The function generates all links to the reliability network. The function calculates the length of the system. The function function $w=\operatorname{conversion}(n, v)$ converts the value of the input argument $n$ from base 10 to base 2 and stores the result of the conversion in the variable $\mathrm{w}$.

The function function val=fstruct $(x)$ receives the input vector $x$ of the structure function variables and returns the value of the structure function.

The display of links is made by the function function write(n,w,tip).

The function function $w=i n v e r s e(v)$ inverts the vector $\mathrm{v}$ and stores the result in the vector $\mathrm{w}$.

The function function printnl(nb) displays the number of links with $k$ elements, $k=1,2, \cdots$

We present below the Matlab code for implementing the algorithm.

$\%$ The main function

function links(n)

clc;

$\mathrm{k}=2^{\wedge} \mathrm{n}$;

for $\mathrm{i}=1: \mathrm{n}$

$\mathrm{v}(\mathrm{i})=0$;

end

ival=1;

for $\mathrm{i}=0: \mathrm{k}-1$

$\mathrm{w}=$ conversion $(\mathrm{i}, \mathrm{v})$;

val=fstruct $(w)$;

if $\mathrm{val}==1$

$\operatorname{vval}($ ival) $=\mathrm{i}$;

fprintf(' The value \%d : $\ln \mathrm{y}=\mathrm{f}(\mathrm{l}, \mathrm{i})$;

$\mathrm{nb}$ (ival) $=0$;

for $j=1$ :length(w)-1

fprintf(' \%d , ',w(j));

if $w(j)==1$

$n b($ ival $)=n b($ ival $)+1$;

end

end

if $\mathrm{w}($ length $(\mathrm{w}))==1$

$n b($ ival $)=n b($ ival $)+1$;

end

fprintf(' \%d ',w(length(w)));

fprintf(' ) = \%d $\backslash n$ ',val);

write(i,w,'l');

ival=ival+1;

end

end

printnl(nb);

fprintf(' The length of the system is \%d

$\backslash$ ',min(nb)); 
end

$\%$ Conversion function

$\%$ from base 10 in base 2

function $\mathrm{w}=$ conversion(n,v)

$\mathrm{i}=1$;

while $\mathrm{n} \sim=0$

$\mathrm{uc}=\bmod (\mathrm{n}, 2)$;

$\mathrm{v}(\mathrm{i})=\mathrm{uc}$;

$\mathrm{i}=\mathrm{i}+1$;

$\mathrm{n}=$ floor(n/2);

end

$\mathrm{w}=$ inverse (v);

end

\% Function for reversing vector v

function $\mathrm{w}=$ inverse(v)

$\mathrm{n}=$ length(v);

for $i=1: n$

$\mathrm{w}(\mathrm{i})=\mathrm{v}(\mathrm{n}-\mathrm{i}+1)$;

end

end

\% Function for displaying links

function write(n,w,tip)

$\mathrm{p}=$ length $(\mathrm{w})$;

if tip=='l'

fprintf(' Subassembly $\mathrm{L}=\{$ ');

for $i=1: p$

if $w(i)==1$

fprintf(' e\%d ',i);

end

end

fprintf(' \} is a link $\backslash n$ ');

end

end

$\%$ Function to display the number of links

$\%$ with k elements

$\% \mathrm{k}=1,2, \ldots$

function printnl(nb)

$\mathrm{kmin}=\min (\mathrm{nb})$;

$\operatorname{kmax}=\max (\mathrm{nb})$; for $\mathrm{i}=\mathrm{kmin}: 1: \mathrm{kmax}$

$\mathrm{s}=0$;

for $\mathrm{j}=1$ :length(nb)

if $n b(j)==i$ \& $n b(j) ~=0$

$\mathrm{s}=\mathrm{s}+1$;

end

end

fprintf(' Number of links with \%d elements

$\left.=\% \mathrm{~d} \backslash \mathrm{n}^{\prime}, \mathrm{i}, \mathrm{s}\right)$;

end

end

\% Function of system structure

function val=fstruct $(\mathrm{x})$

$\mathrm{val}=\mathrm{x}(5) *(1-(1-\mathrm{x}(3) * \mathrm{x}(4)) *(1-\mathrm{x}(1) * \mathrm{x}(2)))$;

end

\section{Case study}

Consider the system $S=(E, \varphi)$ with the properties: $n=5, \quad E=\left\{e_{1}, e_{2}, e_{3}, e_{4}, e_{5}\right\}$, $X=\left\{x_{1}, x_{2}, x_{3}, x_{4}, x_{5}\right\}$. The graph of the system is shown in Figure 1.

Obviously, the structure function of the system is the function: $\varphi: X \rightarrow\{0,1\}$, $\varphi\left(x_{1}, x_{2}, x_{3}, x_{4}, x_{5}\right)=x_{5} \times\left(1-\left(1-x_{1}\right.\right.$.

$\left.\left.x_{2}\right) \times\left(1-x_{3} \times x_{4}\right)\right)$

For manual determination of all system links, the values of the structure function are calculated at all points $\left(x_{1}, x_{2}, x_{3}, x_{4}, x_{5}\right)$. If for

$x_{i_{1}}=x_{i_{2}}=\cdots=x_{i_{p}}=1$ and $x_{i}=0$

for any

$i \in\{1,2, \cdots, n\} \backslash\left\{i_{1}, i_{2}, \cdots, i_{p}\right\} \quad$ and $\varphi\left(\mathrm{x}_{1}, \mathrm{x}_{2}, \cdots, \mathrm{x}_{\mathrm{n}}\right)=1$ then the subassembly of elements $\left\{e_{i_{1}}, e_{i_{z}}, \cdots, e_{i_{p}}\right\}$ is a link.

Table 1 is completed and all system links are

obtained.

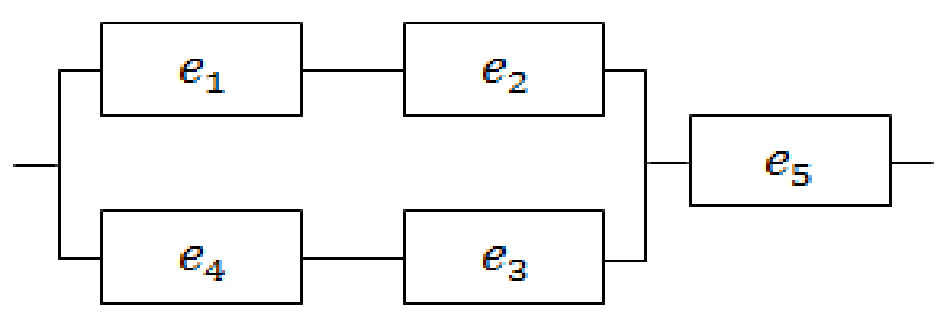


Figure 1: The system

\begin{tabular}{|c|c|c|c|c|c|c|c|}
\hline Value & $x_{1}$ & $x_{2}$ & $x_{3}$ & $x_{4}$ & $x_{5}$ & $\varphi$ & Links \\
\hline 0 & 0 & 0 & 0 & 0 & 0 & 0 & \\
\hline 1 & 0 & 0 & 0 & 0 & 1 & 0 & \\
\hline 2 & 0 & 0 & 0 & 1 & 0 & 0 & \\
\hline 3 & 0 & 0 & 0 & 1 & 1 & 0 & \\
\hline 4 & 0 & 0 & 1 & 0 & 0 & 0 & \\
\hline 5 & 0 & 0 & 1 & 0 & 1 & 0 & \\
\hline 6 & 0 & 0 & 1 & 1 & 0 & 0 & \\
\hline 7 & 0 & 0 & 1 & 1 & 1 & 1 & $\left\{e_{3}, e_{4}, e_{5}\right\}$ \\
\hline 8 & 0 & 1 & 0 & 0 & 0 & 0 & \\
\hline 9 & 0 & 1 & 0 & 0 & 1 & 0 & \\
\hline 10 & 0 & 1 & 0 & 1 & 0 & 0 & \\
\hline 11 & 0 & 1 & 0 & 1 & 1 & 0 & \\
\hline 12 & 0 & 1 & 1 & 0 & 0 & 0 & \\
\hline 13 & 0 & 1 & 1 & 0 & 1 & 0 & \\
\hline 14 & 0 & 1 & 1 & 1 & 0 & 0 & \\
\hline 15 & 0 & 1 & 1 & 1 & 1 & 1 & $\left\{e_{2}, e_{3}, e_{4}, e_{5}\right\}$ \\
\hline 16 & 1 & 0 & 0 & 0 & 0 & 0 & \\
\hline 17 & 1 & 0 & 0 & 0 & 1 & 0 & \\
\hline 18 & 1 & 0 & 0 & 1 & 0 & 0 & \\
\hline 19 & 1 & 0 & 0 & 1 & 1 & 0 & \\
\hline 20 & 1 & 0 & 1 & 0 & 0 & 0 & \\
\hline 21 & 1 & 0 & 1 & 0 & 1 & 0 & \\
\hline 22 & 1 & 0 & 1 & 1 & 0 & 0 & \\
\hline 23 & 1 & 0 & 1 & 1 & 1 & 1 & $\left\{e_{1}, e_{3}, e_{4}, e_{5}\right\}$ \\
\hline 24 & 1 & 1 & 0 & 0 & 0 & 0 & \\
\hline 25 & 1 & 1 & 0 & 0 & 1 & 1 & $\left\{e_{1}, e_{2}, e_{5}\right\}$ \\
\hline 26 & 1 & 1 & 0 & 1 & 0 & 0 & \\
\hline 27 & 1 & 1 & 0 & 1 & 1 & 1 & $\left\{e_{1}, e_{2}, e_{4}, e_{5}\right\}$ \\
\hline 28 & 1 & 1 & 1 & 0 & 0 & 0 & \\
\hline 29 & 1 & 1 & 1 & 0 & 1 & 1 & $\left\{e_{1}, e_{2}, e_{3}, e_{5}\right\}$ \\
\hline 30 & 1 & 1 & 1 & 1 & 0 & 0 & \\
\hline 31 & 1 & 1 & 1 & 1 & 1 & 1 & $\left\{e_{1}, e_{2}, e_{3}, e_{4}, e_{5}\right.$ \\
\hline
\end{tabular}

To determine the length of the system, the numbers are determined:

$l_{3}=2$ because there are two links each with three elements (links: $\left\{e_{3}, e_{4}, e_{5}\right\}$ and $\left\{e_{1}, e_{2}, e_{5}\right\}$; $l_{4}=4$ because there are four links each with four elements (links: $\left\{e_{2}, e_{3}, e_{4}, e_{5}\right\},\left\{e_{1}, e_{3}, e_{4}, e_{5}\right\},\left\{e_{1}, e_{2}, e_{4}, e_{5}\right\}$ and $\left\{e_{1}, e_{2}, e_{3}, e_{5}\right\}$ );

$l_{5}=1$ because there is only one link to five elements (link: $\left\{e_{1}, e_{2}, e_{3}, e_{4}, e_{5}\right\}$ ). 
The $S$ system length is equal to: $\lambda(S)=\min \left\{k \mid l_{k}>0\right\}=\min \{3,4,5\}=3$

Using the Matlab function above, we will determine all the links of this system and the length of the system.

The structure function denoted by $\varphi$ coincides with the function denoted by $f$ in the Matlab code.

An example of execution is:

$>>$ links(5)

The value 7 :

$\mathrm{y}=\mathrm{f}(0,0,1,1,1)=1$

Subassembly $L=\{$ e3 e4 e5 $\}$ is a link

The value 15 :

$y=f(0,1,1,1,1)=1$

Subassembly $\mathrm{L}=\{$ e2 e3 e4 e5 $\}$ is a link

The value 23 :

$y=f(1,0,1,1,1)=1$

Subassembly L $=\{$ e1 e3 e4 e5 $\}$ is a link

The value 25 :

$\mathrm{y}=\mathrm{f}(1,1,0,0,1)=1$

Subassembly $\mathrm{L}=\{$ e1 e2 e5 $\}$ is a link

The value 27 :

$y=f(1,1,0,1,1)=1$

Subassembly $\mathrm{L}=\{$ e1 e2 e4 e5 $\}$ is a link

The value 29 :

$y=f(1,1,1,0,1)=1$

Subassembly $L=\{$ e1 e2 e3 e5 $\}$ is a

link

The value 31 :

$y=f(1,1,1,1,1)=1$

Subassembly $L=\{$ e1 e2 e3 e4 e5 $\}$ is a

link

Number of links with 3 elements $=2$

Number of links with 4 elements $=4$

Number of links with 5 elements $=1$

The length of the system is 3
It is easy to see that the linkages generated by the Matlab function coincide with the links determined manually in Table 1.

Also, the length of the system determined with the Matlab function coincides with the one determined manually.

\section{Conclusions}

Let $\quad n \in N^{*}, \quad E=\left\{e_{1}, e_{2}, \cdots, e_{n}\right\}$,

$X=\left\{x_{1}, x_{2}, \cdots, x_{n}\right\}$, function $\varphi: X \rightarrow\{0,1\}$,

$y=\varphi\left(x_{1}, x_{2}, \cdots, x_{n}\right), \quad$ and the system

$S=(E, \varphi)$.

It's called the dual system of the system $S=(E, \varphi)$ the system $S^{d}=\left(E, \varphi^{d}\right)$

where the structure function $\varphi^{d}: X \rightarrow\{0,1\}$ is defined by

$$
\begin{aligned}
& \varphi^{d}\left(x_{1}, x_{2}, \cdots, x_{n}\right)=1-\varphi\left(1-x_{1}, 1-\right. \\
& \left.x_{2}, \cdots, 1-x_{n}\right)
\end{aligned}
$$

One of the developments in this article is the automatic determination of the links and length of the dual system of a given system. Another development is the determination

of the minimal links of the $S=(E, \varphi)$

system and its dual $S^{d}=\left(E, \varphi^{d}\right)$ system.

\section{Acknowledgements}

The author thanks this way to all those who contributed in one way or another to the elaboration of this work.

\section{References}

[1] Cătuneanu, V.,M., Mihalache, A., Bazele teoretice ale fiabilităţii, Ed. Academiei, 1983, București, România. 
[2] Panaite, V., Popescu, M.,O., Calitatea produselor şi fiabilitate, Ed. Matrix Rom, 2003, Bucureşti, România.

[3] Ţârcolea, C., Filipoiu, A., Bontaş, S., Tehnici actuale în teoria fiabilităţtii, Ed. Ştiinţifică şi Enciclopedică, 1989, București, România.

[4] Vasiliu P., Deliu F., Funcţie Matlab pentru determinarea legăturilor unei rețele de fiabilitate, Buletinul AGIR nr. 4/2017, pag. 24-27.

[5] Vasiliu, P., Programare în Matlab, Ed. ANMB, 2015, Constanţa, România. 